\title{
The role of men in families: achieving gender equity and supporting children
}

\section{Patrice L Engle}

Fathers and men in families represent one of the most important resources for children's wellbeing. Social services, including development interventions in the South, have hitherto failed to take into consideration the major role of men in families, and its effects on women, on children, and on the men themselves.

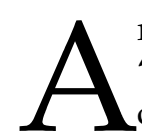

recent UNICEF report concludes, 'If UNICEF is going to continue to contribute to development goals and gender equality...there will have to be greater efforts to involve men' (Richardson, 1995, p. 6). Similar concerns have been raised by the Ford Foundation, Save the Children, and many other NGOs. That men should be involved in reproductive health programmes was a major recommendation from the Cairo Conference on Population and Development. Despite this interest, social service and health programmes continue to target mothers and children, ignoring the role of men in the lives of children.

In recent years, most development interventions focusing on the well-being of the family have stressed the importance of the mother/child relationship, even in societies in which the father controls decisions about the household and family welfare. Economic instability, and the inability of institutions in both developed and developing countries to increase their contributions to families, have led to a search for additional sources of support for children (Bruce et al., 1995). The efforts on the part of the state, and many development organisations, to improve the welfare of children by increasing male income proved to be less effective than originally expected in terms of improving children's nutritional status and health (Marek, 1992).

Not only has the income of men not benefited children as much as expected; women are more likely to use their income for the well-being of children than are men (e.g., Jackson, 1996). Agencies have sponsored income-generating projects for women, and the provision of credit for poor women. However, while approaches which focus on women have had many benefits both for women and for children, there is considerable evidence that this focus may increase the workload of already overburdened women, reducing their personal well-being and their ability to care for their children (McGuire and Popkin, 1990).

This article surveys programme initiatives, conferences, research, and 
publications concerned with the role of men in the family, organised by agencies such as UNICEF, The Population Council, and the Consultative Group for Early Childhood Care and Development.

\section{Social fatherhood}

The concept of 'father' needs to be widened from a biological role to one which emphasises socialisation and support of many kinds during childhood. Although this nurturing aspect of 'fatherhood' is recognised across cultures, the person who plays the father role may or may not be the biological father. Responsibility for children may fall to the mother's brother; or older male kin such as the grandfather (Richardson, 1995). A 'social father' may take responsibility for all of the children a woman has, even though some were biologically fathered by another man. The narrow concept of 'father' could thus be appropriately replaced with 'men in families'.

Four of the major contributions men make to family life are: taking economic responsibility for children, building a caring relationship with children, reducing the chances of 'unpartnered fertility', ${ }^{1}$ and ensuring gender equality in the family (Family Impact Seminar, 1995; Richardson, 1995). The absence of any of these will represent a problem for children's development; while taking such roles can enhance the lives of men. This new perspective has been seen as a threat by feminists and others who have struggled long and hard to bring women's issues to the forefront (Engle, 1995).

\section{Fathers in families}

The percentage of female-headed households in developing countries ranges from about 10 to 25 per cent, and has increased gradually over the last decade (Bruce et al, 1995). The highest rates of female head- ship are reported in the African countries of Botswana (46 per cent), Swaziland (40 per cent), Zimbabwe (33 per cent), and the Caribbean countries such as Barbados (44 per cent) and Grenada (43 per cent). Some rates in the developed countries are equally high, ranging from 38 per cent in Norway, 30 per cent in Germany, and 32 per cent in the United States (United Nations, 1995).

Many of these statistics reflect patterns of family formation which differ from the Western model of a nuclear family. In Botswana, which has a high rate of female headship, mothers live with their natal families until their partners are well into their forties (many men are migrant workers in South African mines). Even though support is customarily provided by the mother's family, these families are still reported as female-headed.

However, residence of the father within the household does not always imply either an economic contribution to his family, or involvement with his children. In the Caribbean, for example, many men contribute to their children's upkeep, but have only a visiting relationship with their children's mother; whereas others may be co-resident in a household, but provide no economic support for the family due to poverty, lack of employment, or spending on alcohol or drugs (Brown et al, 1994). Research shows that if the presence of the father is to have a positive effect, this requires some involvement of the father with the child (e.g. Levine et al., 1993). Research and programme efforts need to look at the relationship between father and child, rather than just co-habitation.

\section{Forces affecting the family}

Two forces which may influence family formation and the role of men in families, are urbanisation, and changing patterns in women's employment, with underemployment of men. Urbanisation is charac- 
teristic of the industrialised regions of the world, which UN statistics cite as 77-78 per cent urban. South America is equally urban: rural, as is Northern Africa; and the rest of Africa and Asia are between 28 and 33 per cent urban (United Nations, 1995). Urban populations are growing in all areas, especially in sub-Saharan Africa and Asia.

The changing gender composition of the workforce in developing countries is likely to have significant effects for men's roles (Evans, 1995). In the past two decades, women's employment, as measured in national census surveys (primarily formal employment) has increased in all areas, except sub-Saharan Africa and Eastern Asia. In comparison, men's economic activity rates have declined significantly everywhere except central Asia (e.g., US 81 to 75 per cent, Latin America 85 to 82 per cent, Southern Asia 88 to 78 per cent) (United Nations, 1995).

\section{Effects of fathers on children}

\section{Building a caring relationship and child-care}

In the literature, 'father involvement' normally refers to the establishment of warm and close relationships between fathers and their children. This can be accomplished with relatively little time investment; the most important ingredient appears to be positive emotion and attention to children. Although infants initially show preference for mothers over fathers, infants become attached to their fathers by the end of the first year of life, even if the fathers spend relatively little time with them (Cox et al, 1992).

In the US and Europe, studies have reported that fathers who were involved with their children contribute greatly to their children's intellectual, social, and emotional development. Easterbrooks and Goldberg (1985) found that the quality of the interaction (the father's sensitivity to the toddler's needs) was a better predictor of the children's cognitive performance than the amount of time spent with the child.

For men in many parts of the world, to have a 'caring relationship' with an infant or young child is a novel expectation. For example, some participants at a seminar in Lesotho in 1991 felt that the interactions that African men have with very young children are rare, accidental, and of little importance. (Bernard van Leer Foundation, 1992).

For example, fathers in Zimbabwe, were surprised to learn that they 'should' play with their children from birth onward; they expected to wait until the children could talk. However, for older children, the pattern changes: in most African countries, fathers and grandfathers train older sons.

\section{Fathers' time in infant and child care}

Worldwide, fathers spend significantly less time in child care than mothers. Barry and Paxson (1971) summarised ethnographic reports from 186 cultures, and found that the percentage of cultures in which fathers had 'regular, close relationships' during infancy was 2 per cent, and 5 per cent in early childhood, although the percentage in which fathers were in frequent close proximity was much higher (32 per cent for infants, 52 per cent for young children).

However, some fathers do spend time performing child-care activities. Jahn and Aslam (1995) observed men living in squatter settlements in Karachi, Pakistan. In 75 per cent of observations of children being carried, the man was the carrier, even when the woman was present. How these patterns change with urbanisation and increased maternal employment (and decreased paternal employment) will be important to investigate; new expectations for father involvement may emerge if alternative providers of child-care are unavailable.

\section{Effects on fathers themselves}

One of the benefits of the changing roles for men in families is increased closeness to children. An extreme case is repres- 
ented by men who take primary care for their children. This number is small, but is continually growing. These men often did not choose the role, but many express how much the experience has meant to them, and the importance of their attachment to their children (e.g., Davis and Chavez, 1995, for Hispanic men in the US).

\section{Economic support for children}

\section{Female-headed households}

A contribution to household income from fathers tends to be associated with improved child status; female-headed and maintained households with children are generally poorer than families with a male head, although there is considerable variation depending on the social and economic context of the female heads .

It is a truism in development circles that female-headed households are among 'the poorest of the poor'. This point has recently been questioned, in relation to the degree of economic poverty, but also in relation to the degree of access that such households have to decision-making within their communities and in wider society (Varley 1996). Certainly, children in female-headed households are not always worse nourished than those in male-headed households. Studies show that negative effects of female headship are seen in Latin America, but not subSaharan Africa (Desai, 1991).

Studies have shown that although the father's income may have a positive effect on food expenditures and child wellbeing, these effects may be smaller than if the income were under the mother's control (Hoddinott and Haddad, 1995; Buvinic et al, 1992). Women may be more likely to perceive children's needs, may develop stronger attachment to the child, and social roles may dictate that women are responsible for obtaining food for children (Engle, 1990).
In Kenya and Malawi, despite lower incomes, a smaller percentage of children in female-headed households were malnourished than in male-headed households (Kennedy and Peters, 1992). In Botswana, children in female-headed households received more education than children in male-headed households (Kossoudji and Mueller, 1983).

\section{Costs of father's presence}

The presence of the father is not always a positive force in either women's or children's lives. Women may improve their situation and that of their children by leaving an abusive partner. In a collection of studies of violence against women worldwide, rates ranged from 20 to 60 per cent (Heise, Pitanguy and Germain, 1994). It is possible that abuse of children is more common if a man is present in the family.

The cost to the family of the father's consumption of food and resources may be a drain on the family budget, particularly if he is not employed or is spending money on alcohol or cigarettes .

\section{Avoidance of 'unpartnered fertility}

The third contribution that men can make to responsible fatherhood is to avoid sexual encounters which risk the birth of unplanned and unwanted children. Few cultures emphasise sexual restraint on the part of youngmales. Rather than encouraging the use of contraception and sex education to prevent the birth of unwanted children, traditional cultures attempt to protect young women through a combination of strict religious constraints on sexuality, or very early marriage (Richardson, 1995).

When pregnancies do occur, families may put great pressure on the couple to form a relationship. However, increased acculturation and urbanisation may undermine these supports. In a rural Guatemalan community, the rate of 
unpartnered fertility has doubled in the past decade, from 6 per cent to 12 per cent (Engle and Smidt, 1996). In the US, among teen mothers, 67 per cent of 'traditional' Hispanics were married, compared to only 44 per cent of 'non-traditional' Hispanics (Mirande, 1988).

\section{Effects of gender inequality in the home}

Gender inequality in the home, (i.e.men having a greater amount of authority in decision-making) has been associated with increased rates of domestic violence or restriction of life opportunities for women. Patriarchal control is often associated with low rates of schooling for girls, low status of women, early age of marriage, and high rates of malnutrition for children (Ramalingaswami et al, 1996).

Despite similar levels of income and health care services in sub-Saharan Africa and South Asia, rates of malnutrition in South Asia are almost twice as high. The authors explain this 'Asian enigma' as a consequence of the extreme subordination of women in South Asia: 'Judgment and self-expression and independence largely denied, millions of women in South Asia have neither the knowledge nor the means nor the freedom to act in their own and their children's best interests' (ibid., 15).

\section{Ways forward: promoting committed fatherhood}

\section{International advocacy}

Internationalconferences-suchasUNICEF's Innocenti Global Seminar (Richardson, 1995), and the Population Council's Taller Para Padres Responsables (Workshop on Responsible Fatherhood) (Engle and Alatorre Rico, 1994) - are opening the debate. The groundwork was laid for including men in reproductive health programmes at the Cairo International Conference on Population and Develop- ment (Richardson, 1995). Now many groups are including fathers in their plans. However, gender equity must be included in all these discussions.

\section{Legal protection for children}

Establishing protection for children of absent fathers may be quite difficult (Folbre, 1992). For example, in Mexico this lack of protection is due to the deficiency of Mexican law (Brachet-Marquez, 1992). Desertion is necessary in order to seek an award for child support, but is not recognised in law if the husband returns within six months. This means a man can come and go for years as long as he spends one night every six months at home.

If a husband chooses to stop paying to support his child, the burden of initiating legal procedures falls on the wife. Many husbands simply claim insolvency (ibid), and monitoring fathers' income is extremely difficult. The scarcity of employment in Mexico has resulted in more and more men earning untraceable non-wage money. Similar problems occur in other countries.

\section{Promoting caring relationships}

A community-based effort to build and support fathering skills has been remarkably successful in the Caribbean. The Caribbean Child Development Centre has established fathers' groups, which have formed an organisation called Fathers Inc. Fathers, who are often non-resident with their families, follow a curriculum to learn parenting skills (Brown et al, 1994). Reasons for the success of the groups are that they are men-only, and are initiated by men's interest in their children (Caribbean Child Development Center, 1994).

A second strategy is to bring fathers into schools and day-care centres, to help with child care. To be effective at building caring relationships, these programmes must increase fathers' interaction with their children, rather than simply allowing men to take part in the same activities as their children side-by-side. 
Kavanaugh (1992) describes a project to create father and child nights at a day-care centre in New Mexico, USA. The success of the programme was attributed to balancing discussion with activities, promoting attendance by making contact with men face-to-face to invite them, having a male member of staff, and making a formal contract with the fathers to attend.

Levine et al (1993) created a manual promoting methods to encourage the involvement of biological fathers, or 'father substitutes', in pre-school programmes in the US for low-income children. Some of his suggestions include becoming aware of cultural limitation on the father role, providing men with a variety of ways of being involved, keeping open to various kinds of men in the child's life (e.g. grandfathers), and becoming aware of resistance both in the staff and among the mothers to men's involvement.

Experimental studies have shown that short-term programmes focusing on child development and fathering can have significant effects. Marked improvement was seen in the relationship of fathers to adolescents in Cameroon (Nsamenang, 1992), to newborns and young infants after prenatal education in the US (Parke et al 1979), and to pre-school-aged children after a ten-week father-only programme in the US (McBride,1991). These fathers reported feeling more responsible for daily decisions about their children, the kind of involvement which men are least likely to achieve. The most effective programmes were those which included mothers in separate training, since the changes involved both parents.

\section{Combining fatherhood development and job-training skills}

Because a primary cause of lack of support for children appears to be too many obligations for men, programmes in the US have attempted to increase low- income unwed fathers' payment of child support through combined job training, job placement, payment enforcement, and fatherhood education projects (e.g., the Public/Private Ventures Project, Achatz and MacAllum, 1994). Despite great difficulties in recruiting fathers into the programme, the results have been encouraging: child-support payments have increased, and men's feelings about themselves have improved (ibid). This programme included a component labelled the Fatherhood Development Curriculum. Once a week, the men in the project met to discuss issues of manhood and fatherhood, and consider the mother's perspective.

\section{Educating children in broader gender roles}

Education for children in responsible fatherhood is likely to have a lower (social and economic) cost than redressing current problems through direct re-education for fathers. Klinman (1986) developed a plan to give boys in junior high and high school (11-18) experience with young children through working in pre-school programmes. In many societies, young men are used as child-care providers as well as young women, and this helps their ability to nurture.

\section{Establishing rights to paternity leave}

Another strategy to increase father involvement is to promote child-care leave for fathers, either paid or unpaid, and flexible working hours. However, such opportunities are used by only about 10 per cent in the US and Sweden (Pleck, 1985). The low usage of paternal child-care leave may be due to prejudice by employers, the desire of the wife to stay at home, or possible loss of income for the father.

Father involvement at this stage also has the obvious benefit of alleviating the workload of mothers. An approach which had this aim was a Save the Children project in Vietnam (Richardson, 1995). Husbands were told that they could 
reduce the health-care costs for their children if their wives were to work less during pregnancy and immediately postpartum. In the communes which received the messages, women had significantly more rest days while pregnant, and higher birthweight babies, and men felt more empowered to help their wives.

\section{Paternity as an issue for social services}

As stated earlier, a bias noted frequently by researchers into fathering has been the exclusive attention to mothers and children within much of the health and social service literature. According to Bolton (1986), in the social service field in the US, men are either providers, the 'good guys', or they are not providers, in which case they are the 'bad guys'. There is little awareness that some men may choose to stay at home to take care of children, or may be unable to work due to unemployment, lack of training, or disability. Social services need to recognise that many fathers are trying to meet their obligations; there are only a few 'bad' ones. They themselves may be in need of help; inability to meet the demands of being a provider often drives men away from paternal responsibilities. In health-care services, the role and significance of the father, which varies according to cultural context, needs to be understood if health-care provision is to be appropriate and uptake maximised. The role of the father may be significant. For example, in the US the father's opinion was one of the most important indicators of whether a mother went for prenatal care (Sable et al , 1990) and breastfed. One recommendation from Pakistan is to develop a two-pronged approach, continuing outreach to women, but adding outreach to men (Jahn and Aslam, 1995).

In Vietnam, it was found that men had very little knowledge of UNICEF's 'Facts for Life'. UNICEF organised a contest for men, to survey knowledge of these issues, and write an essay. About 47,000 entries were received. In the months following the contest, oral rehydration therapy (ORT) use increased by 60 per cent, and child immunisation rose to 90 per cent. Grandfathers were particularly interested in increasing their involvement with children (reported in Richardson, 1995).

\section{Encouraging paternal responsibility'}

Following recommendations from Cairo, reproductive health programmes have begun to target sex education messages to men as well as to women. There is some concern that giving men the messages will simply disempower women again, after years of struggling to place reproductive control in the hands of women. Gender equity as well as increasing the role of men must be the focus.

There is also a growing attempt by governments to establish male paternity at the time of the child's birth. In one successful example in the US, almost twothirds of unmarried parents voluntarily acknowledged paternity if they were provided the opportunity during the first few days postpartum (Family Impact Seminar, 1995).

\section{Promoting gender equality}

The strongest predictor of improved gender equity in the home is women's education (Richardson, 1995) and related income-earning. Thus, increasing access to education for girls has been a major focus of international pressure. In South Asia, women's combined disadvantages of lack of education, dowry, and young age at marriage (10-14) result in low status in the family. In Rajasthan, India, a UNICEF project promoted education for girls and delaying the age of marriage. As a result of two- or three-day visits and awareness-raising by a team of five women, who met with male village 
leaders and visited house-to-house, the number of adolescent girls in school increased, and the number of marriages decreased (Richardson, 1995).

UNIFEM and the Bahai church were able to change men and women's views about traditional male and female roles in Malaysia, Bolivia, and Cameroon through the use of drama and song, and consultation. Men were helped to understand the disproportionate workloads of women. As a result, spouse abuse and alcoholism have declined (Richardson, 1995).

\section{Conclusions}

At last, the critical role of men in families for the well-being of children, women, and of the men themselves is being recognised. Men's involvement in the 'private sphere' of the household and family is as crucial to economic and social development as the involvement of women in the 'public sphere' of incomegeneration and community decisionmaking. Furthermore, the two are interlinked: many successful development projects promoting women's participation outside the home have been aided by support from sympathetic men. In the absence of such support, the potential benefits for women, children and men themselves are jeopardised.

There are a number of techniques which can be used to support men in their parenting role while promoting gender equity in the home, but these issues must be linked. Perhaps the most effective will be those which are preventative, which work with the next generation of mothers and fathers to expand their roles and stress the importance of both parents' contributions. Following Barker et al's recommendation from Rio de Janeiro (1995), we need to support the non-traditional men who are striving to construct new rolemodels for themselves. The benefits to current fathers, to their partners, and to their children of their involvement with young children suggests that we must work in this direction.

Patrice Engle teaches at Cal Poly State University, San Luis Obispo, CA

e-mail:pengle@cymbal.aix.calpoly.edu

\section{Notes}

1 'Unpartnered fertility' is the procreation of children with a biological mate with whom the other parent does not have a social relationship.

\section{References}

Achatz, M and MacAllum, C A (1994) Young Unwed Fathers: Report from the Field, Phila, Pa: Public/Private Ventures.

Barker, G, Loewenstein, I, and Ribeiro, M (1995) 'Where the boys are: Attitudes related to masculinity, fatherhood, and violence toward women among low income adolescent males in Rio de Janeiro, Brazil', Mimeo.

Barry, H, and Paxson, L M (1971) 'Infancy and early childhood: Cross-cultural codes: 2', Ethnology 10, 466-508.

Bernard van Leer Foundation, (1992) 'Where have all the fathers gone?' Newsletter 65.

Bolton, F G (1986) 'Today's father and social services delivery system: A false promise', in ME Lamb (ed) The Father's Role: Applied Perspectives. New York: John Wiley.

Brachet-Marquez, V (1992) Absentee Fathers: A Case-based Study of Family Law and Child Welfare in Mexico PC/ICRW working paper series. Family Structure, Female Headed and Maintained Families and Poverty.

Brown, J, Bloomfield, R, and Ellis, O (1994) Men and Their Families: Contributions of Caribbean Men to Family Life, West Indies: Sprectrum Graphics. 
Bruce, J, Lloyd, C B, and Leonard, A, with Engle, P L, and Duffy, N (1995) Families in Focus: New Perspectives on Mothers, Fathers and Children, New York: Population Council.

Buvinic, M, Valenzuela, J P, Molina, T, and Gonzales, E (1992) 'The fortunes of adolescent mothers and their children: The transmission of poverty in Santiago, Chile' Population and Development Review 18, 269-297.

Caribbean Child Development Centre, School of Continuing Studies (1994) Men and Their Families: Discussion Guide for Use by Groups in Church, School, Community and Other Settings, Kingston, Jamaica: University of the West Indies.

Cox, M J, Owen, M T, and Henderson, V K (1992) 'Prediction of infant-father and infant-mother attachment' Developmental Psychology 28, 474.

Davis, S K, and Chavez, V (1995) 'Hispanic househusbands', in A M Padilla (ed) Hispanic Psychology: Critical Issues in Theory and Research, Thousand Oaks: Sage (pp. 257-287).

Desai, S (1991) Children at Risk: The Role of Family Structure in Latin America and West Africa, New York: Population Council Working Papers No. 28.

Easterbrooks, M A, and Goldberg, W A (1985) 'Effects of early maternal employment on toddlers, mothers, and fathers Developmental Psychology 21, 774-783.

Engle, P L (1995) 'Mother's money, fathers' money, and parental commitment: Guatemala and Nicaragua', in R Blumberg, C A Rakowski, I Tinker, and M Monteon (eds) Engendering Wealth and Well-being, Boulder, Colo:Westview (pp. 155-180).

Engle, P L (1995) Men in Families: Report of a Consultation on the Role of Males and Fathers in Achieving Gender Equality, New York: UNICEF.

Engle, P L, Hurtado, E, and Ruel, M (1995) 'Smoke exposure of women and children in highland Guatemala:
Measurement Issues'. Submitted for publication.

Engle, P L (1993) 'Influences of mothers' and fathers' income on child nutritional status in Guatemala', Social Science and Medicine 37: 11, pp.1303-1312.

Engle, P L and Alatorre Rico, J (1994) Taller Sobre Paternidad Responsable (workshop on responsible fatherhood). The Population Council/International Center for Research on Women Technical Paper Series, May.

Engle, P L, and Breaux, C (1994) Is There a Father Instinct? Fathers' Responsibility for Children, New York: Population Council Series.

Engle, P L (1990) 'Intra-household allocation of resources: Perspectives from psychology' in B L Rogers and N P Schlossman (eds) Intra-Household Resource Allocation (pp. 63-79). Tokyo: United Nations University Press.

Engle, P L and Smidt, R (1996) Consequences of Women's Family Status for Mothers and Daughters in Guatemala, Technical Report, The Population Council, New York/International Center for Research on Women Series (also to be translated into Spanish and published).

Evans, J (1995) 'Men in the lives of children', Coordinators' Notebook 16, 1-20.

Family Impact Seminar (1995) Disconnected Dads: Strategies for Promoting Responsible Fatherhood, Washington, DC: Family Impact Seminar Background Briefing Report.

Folbre, N (1992) 'Rotten kids, bad daddies, and public policy'. (Paper for the International Food Policy Research Institute-World Bank Conference on Intrahousehold Resource Allocation, Washington, DC)

Heise, L, Pitanguy, J, and Germain, A (1994) Violence Against Women: The Hidden Health Burden, World Bank Discussion Paper 255. Washington DC: World Bank. 
Hoddinott, J and Haddad, L (1995) 'Does female income share influence household expenditures? Evidence from Cote d'Ivoire', Oxford Bulletin of Economics and Statistics 57: 1, 77-96.

Jackson, C (1996) 'Rescuing gender from the poverty trap', World Development 24: 3 . Jahn, A and Aslam, A (1995) 'Fathers' perception of child health: A case study in a squatter settlement of Karachi, Pakistan', Health Transition Review 5: 2, 191-206.

Kavanaugh, J (1992) 'Getting daddy involved', Bernard van Leer Newsletter $65,10-11$.

Kennedy, E and Peters, P (1992) 'Influence of gender of head of household on food security, health, and nutrition', World Development 20: 8, 1077-1085.

Klinman, D G (1986) 'Fathers and the educational system', in M E Lamb (ed) The father's Role: Applied Perspectives (pp. 413-428), New York: John Wiley .

Kossoudji, S and Mueller, E (1983) 'The Economic and demographic status of female-headed households in rural Botswana', Economic Development and Cultural Change 31, 831-859.

Levine, J A, Murphy, D T, and Wilson, S (1993) Getting Men Involved, New York: Scholastic.

Marek, T (1992) Ending Malnutrition: Why Increasing Income is not Enough, World Bank Africa Technical Department, Population, Health and Nutrition Division, Technical Working Paper No. 5, October.

McBride, B A (1990) 'The effects of a parent education/play group program on father involvement in childrearing', Family Relations 39, 250-256.

McGuire, J S and Popkin, B M (1990) Helping Women Improve Nutrition in the Developing World: Beating the Zero Sum Game, World Bank Technical Paper number 114.

Miller, B C and Bowan S L (1982) ‘Father to newborn attachment behavior in relation to prenatal classes and presence at delivery', Family Relations 31, 71-78.

Mirande, A (1988) 'Chicano fathers: Traditional perceptions and current realities', in P Bronstein and C P Cowan (eds) Fatherhood Today: Men's Changing Role in the Family (pp. 93-106) NY: John Wiley.

Nsamemang, B A (1992) Human Development in a Third World Context, Newbury Park: Sage.

Parke, R D, and Neville, B (1987) 'Teenage fatherhood', in S L Hofferth and C D Hayes (eds) Risking the Future: Adolescent Sexuality, Pregnancy, and Childbearing (pp. 145-173).

Pleck, J (1985) Working Wives/Working Husbands, Beverly Hills, CA: Sage.

Ramalingaswami, V, Jonsson, $\mathrm{U}$ and Rodhe, J (1996) The Asian Enigma: The Progress of Nations, 10-17. (NY: UNICEF).

Richardson, J (1995) Achieving Gender Equality in Families: The Role of Males. Innocenti Global Seminar, Summary Report, Florence, Italy: UNICEF International Child Development Centre, Spedale degli Innocenti.

Sable, M F, Stockbauer, J W, Schramm, W F and Land, G H (1990) `Differentiating the barriers to adequate prenatal care in Missouri, 1987-1988', Public Health Reports 105: 6, 549-555.

Thomas, D (1990) 'Intra-household resource allocation: An inferential approach', The Journal of Human Resources 25, 637-664.

Todd, H (1996) Women at the Center: Grameen Bank Borrowers after one Decade Boulder, Colo: Westview.

United Nations (1995) The World's Women 1995: Trends and Statstics New York: United Nations.

Varley (1996) 'Women heading households: some more equal than others?' World Development 24:3. 